\title{
The relationship between delivery mode and postpartum depression: a systematic review and meta-analysis
}

\author{
Yu-Xin Chen \\ Institute for Hospital Management, Tsing Hua University, Shenzhen Campus, China \\ Pei Zhao \\ Institute for Hospital Management, Tsing Hua University, Shenzhen Campus, China \\ ZhuLiduzi Jiesisibieke \\ Institute for Hospital Management, Tsing Hua University, Shenzhen Campus, China \\ Pei-En Chen \\ Taiwan Association of Health Industry Management and Development \\ Tao-Hsin Tung ( $\square$ ch2876@chgh.org.tw) \\ Ching-Wen Chien \\ Institute for Hospital Management, Tsing Hua University, Shenzhen Campus, China
}

Research article

Keywords: postpartum depression, delivery mode, cesarean section, risk assessment

Posted Date: May 23rd, 2020

DOI: https://doi.org/10.21203/rs.3.rs-30402/v1

License: (c) (1) This work is licensed under a Creative Commons Attribution 4.0 International License. Read Full License 


\section{Abstract}

Background: To assess the relationship between delivery mode and postpartum depression and to examine whether cesarean section (CS) has a higher risk of postpartum depression than vaginal delivery (VD).

Methods: We searched the Cochrane Library, PubMed, and EMBASE from inception to 30 April 2019 without language limitations. Two authors independently selected studies, assessed the quality of included studies, and extracted data. Any disagreements were resolved by discussion with a third author. We used the Newcastle-Ottawa Scale and GRADE methods to assess the quality of the included studies and evidences. This study had four included cohort studies data and carried out fixed-effect model meta-analysis.

Results: The findings demonstrated a significant difference in the risk of postpartum depression between CS and VD. Compared with the control group, the CS group was associated with a higher prevalence of postpartum depression symptoms (Risk Ratio $=1.29 ; 95 \%$ Cl: 1.11-1.51).

Conclusions: The findings supported a relationship between delivery mode and postpartum depression. Particularly, we found that CS is associated with a higher risk of postpartum depression. Therefore, we ought to encourage pregnant women who are without medical indication of CS to select VD.r

Trial registration: The protocol of this systematic review was registered in the PROSPERO under the number CRD42019148154.

\section{Background}

Postpartum period has a high probability for mental disorder. Postpartum depression, first identified by Pitt in 1968, is one of the common complications after giving birth [1]. This symptom may relate to psychological disturbances between mothers and children [2].

From the clinical viewpoint, the delivery mode could be divided into cesarean delivery (CS) and vaginal delivery (VD). CS is a relatively complicated pregnancy outcome compared with VD.

Previous studies identified that CS has a higher risk of postpartum depression than VD [3]. Some other evidence-based studies also showed the same findings about the relationship between the type of delivery and postpartum depression [4-6]. However, some researchers pointed out that there was no obvious association between mode of delivery and maternal postpartum psychiatric disorders [7-8].

In clinical practice, quite a few countries appeal to control the high rate of CS in recent years [3]. When mothers require CS procedures, clinicians should consider the impact of delivery mode on maternal postpartum mental disorders, especially the relationship between CS and postpartum depression. In addition, clinicians should convince pregnant women without medical indications of CS not to select caesarean, the association between delivery mode and postpartum depression is an essential clinical issue. Thus, this study is conducted to explore the impacts of delivery mode on postpartum depression and to compare the risk of postpartum depression in CS and VD.

\section{Methods}

\subsection{Literature search and search strategy}

In this study, we searched the Cochrane Library, PubMed, and EMBASE for relevant studies from inception to 30th April 2019. The search strategy was '((modes of delivery OR delivery mode OR delivery experience OR type of delivery OR delivery or childbirth) AND (cesarean section OR cesarean delivery OR cesarean OR elective cesarean delivery OR emergency cesarean delivery) AND (vaginal delivery OR normal delivery OR normal vaginal delivery OR natural delivery OR vacuum extraction) AND (postpartum depression OR depression OR postpartum OR depression postnatal OR postpartum depressive symptomatology OR maternal depression OR mental disorder))' with no limitations on language. Table 1 shows the details of the search strategy. The protocol of this systematic review was registered in PROSPERO under the number CRD42019148154.

Table 1: The adopted search strategy

\begin{tabular}{|ll|}
\hline Database & Search strategy \\
\hline $\begin{array}{l}\text { PubMed } \\
\text { Cochrane } \\
\text { Library } \\
\text { EMBASE }\end{array}$ & $\# 1$ modes of delivery OR delivery mode OR delivery experience OR type of delivery OR delivery or childbirth \\
& $\begin{array}{l}\text { \#3 cesarean section OR cesarean delivery OR cesarean OR elective cesarean delivery OR emergency cesarean delivery } \\
\text { \#4 postpartum depression OR depression OR postpartum OR depression postnatal OR postpartum depressive symptomatology OR } \\
\text { maternal depression OR mental disorder }\end{array}$ \\
& \#5 \#1 AND \#2 AND \#3 AND \#4 \\
\hline
\end{tabular}

\subsection{Study selection}

Studies were included if they satisfied the following inclusion criteria: (1) these studies belonged to a cohort study design, (2) the exposure group were women delivered by cesarean and the control group were vaginal delivery, and (3) the outcomes of these articles were the number of postpartum depression patients of the exposure group and that of control group, respectively. For all the publications that accord with our inclusion criteria, we scanned their titles and 
abstracts to determine whether they have relevant information, and then read the full text of relevant articles to evaluate whether to include them or not. Two authors (Chen and Tung) independently selected the related studies, and then their differences were resolved by discussing with a third author (Chien). Several remarks are made to clarify our selection strategy: 1) Since our goal was to explore the relationship between delivery mode and postpartum depression, we did not include studies about prenatal or pregnant depression. 2) In the cesarean section could have elective or emergency CS, the difference between them is that elective CS is decided before the operation [9]. 3) We excluded cross-sectional or case-control studies that could not assess the causal relationship between mode of delivery and depression in the postpartum period.

\subsection{Data extraction and quality assessment}

We extracted the following data from the included studies by using an extraction form: first author, publication year, country, database used, study design, study duration, study subjects, and outcomes. We also used the Newcastle-Ottawa Scale (NOS) to assess the quality of the included cohort studies. Three domains (selection of study groups, comparability, and outcome assessment) of the NOS were used to evaluate the quality of the cohort studies [4]. Each item of selection and outcome category could have a maximum of one star, except the comparability, which could have up to two stars. As a result, a high-quality study was awarded with seven or more stars.

\subsection{Interrater reliability for selection and data extraction}

To establish a consistent selection and data extraction, the kappa statistic was used to assess the interobserver reliability between the two independent reviewers, which showed a kappa value of 0.755 for data extraction (95\% confidence interval (Cl): $0.671-0.839)$.

\subsection{Statistical Analysis}

Review Manager 5.3 (The Nordic Cochrane Centre, The Cochrane Collaboration, 2014) was used to conduct the meta-analysis. The risk of postpartum depression is presented in terms of the risk ratio (RR) and $95 \%$ confidence interval (Cl). The I2 statistic, which evaluates the degree of variation across studies due to heterogeneity rather than chance alone [5], was used to assess the heterogeneity. Specifically, if a study's 12 value is higher than $50 \%$, we considered it has substantial heterogeneity and performed random-effects model meta-analysis. On the contrary, if the 12 value of a study is below $50 \%\left(I^{2}=36 \%\right)$, we carried out fixed-effect model meta-analysis. A funnel plot was used to evaluate the publication bias of each outcome. We further used the GRADE (Grading of Recommendations Assessment, Development, and Evaluation) method to summarize and assess the quality and certainty of the available evidence.

\section{Results}

\subsection{Literature Search and Studies Characteristics}

As illustrated in Fig. 1, our search recognized 3352 records after removing duplicates. Four cohort studies were included in this systematic review. Eventually, these four studies offered data for meta-analysis. Particularly, one of the four involved studies had two sets of data that acquired from the CS group and VD group, respectively [6]. We treat these two data sets as two different studies. We combined this study with the other three studies, because all of them had the same outcome indicators. The characteristics of the included studies are summarized in Table 2. As can be seen, the published time of these studies range from 2011 to 2017. All four cohort studies were population-based cohort studies from Iranian, Italy, and China. In addition, all four of the included studies had seven or more stars on the NOS scale and were of high quality.

Table 2. Characteristics of Included studies

\begin{tabular}{|c|c|c|c|c|c|c|}
\hline Number & $\begin{array}{l}\text { First author, } \\
\text { publication year, } \\
\text { country, } \\
\text { database used }\end{array}$ & $\begin{array}{l}\text { Study } \\
\text { Design }\end{array}$ & $\begin{array}{l}\text { Study } \\
\text { Duration }\end{array}$ & $\begin{array}{l}\text { Study } \\
\text { subjects }\end{array}$ & Outcomes & $\begin{array}{l}\text { NOS } \\
\text { Score }\end{array}$ \\
\hline 1 & $\begin{array}{l}\text { Zohreh Sadat, 2014, } \\
\text { Iranian }\end{array}$ & $\begin{array}{l}\text { cohort } \\
\text { study }\end{array}$ & $\begin{array}{l}14 \text { months } \\
\text { (Aug,2007- } \\
\text { Oct,2008) }\end{array}$ & $\begin{array}{l}150 \mathrm{CS} \\
150 \mathrm{VD}\end{array}$ & $\begin{array}{l}\text { There was no relation between delivery mode and postpartum } \\
\text { depression at } 2 \text { and } 4 \text { months after delivery. }\end{array}$ & $\begin{array}{l}\mathrm{S} \square[0 \\
\mathrm{C}[0 \\
\mathrm{O}\end{array}$ \\
\hline 2 & $\begin{array}{l}\text { Hung-Hui Chen,2017, } \\
\text { Taiwan,China }\end{array}$ & $\begin{array}{l}\text { cohort } \\
\text { study }\end{array}$ & $\begin{array}{l}10 \text { years } \\
(J a n, 1999- \\
\text { Dec,2008) }\end{array}$ & $\begin{array}{l}12619 \\
\text { CS } \\
12619 \\
\text { VD }\end{array}$ & $\begin{array}{l}\text { Cesarean birth was associated with an increased risk of postpartum } \\
\text { stress symptoms. }\end{array}$ & 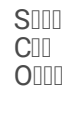 \\
\hline 3 & Ri-hua Xie,2011,China & $\begin{array}{l}\text { cohort } \\
\text { study }\end{array}$ & $\begin{array}{l}8 \text { months } \\
\text { (Feb,2007- } \\
\text { Sep,2007) }\end{array}$ & $\begin{array}{l}415 \mathrm{CS} \\
119 \mathrm{VD}\end{array}$ & $\begin{array}{l}\text { CS is associated with increased risk of postpartum depression in } \\
\text { Chinese women. }\end{array}$ & 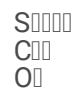 \\
\hline 4 & $\begin{array}{l}\text { Vincenzo } \\
\text { Zanardo,2017, Italy }\end{array}$ & $\begin{array}{l}\text { cohort } \\
\text { study }\end{array}$ & $\begin{array}{l}15 \text { months } \\
\text { (Feb,2014- } \\
\text { May,2015) }\end{array}$ & $\begin{array}{l}256 \mathrm{CS} \\
694 \mathrm{VD}\end{array}$ & $\begin{array}{l}\text { CS } \\
\text { could increase risk of developing early postpartum depressive } \\
\text { symptomatology }\end{array}$ & 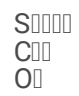 \\
\hline
\end{tabular}

\subsection{Association between delivery mode and postpartum depression}

The four selected studies have the same outcome measures, the number of postpartum depression patients in the exposure groups and that of control groups. The study by Zohreh Sadat et al. Involved 150 patients with CS, 150 control subjects [6]. The study by Ri-hua Xie et al. included 415 patients with CS, 119 
patients with VD [7]. The study by Hung-Hui Chen et al. included 12619 patients with CS, 12619 control subjects [8]. The study by Vincenzo Zanardo et al. included 256 patients with CS and 694 control subjects [11]. As shown in Fig. 2, the fixed effects model meta-analysis demonstrated a significant difference in the risk of postpartum depression between CS and VD. The total RR is $1.29(95 \% \mathrm{Cl}: 1.11-1.51)$. The studies had a small statistical heterogeneity $\left(I^{2}=36 \%\right)$. In addition, the Funnel plot showed little publication bias (test for overall effect: $Z=3.25, P=0.001$ ) (Fig. 3).

\subsection{GRADE Summary of Findings}

The results of the GRADE assessment are summarized in Table 3. Particularly, the quality of the evidence from the included observational studies was initially judged to be low. Meanwhile, all evidence did not have serious of risk of bias, inconsistency, indirectness, imprecision, as well as publication bias, and the quality of all evidence is still low without downgrade.

Table 3. Results of the GRADE assessment

\begin{tabular}{|c|c|c|c|c|c|c|c|c|c|c|}
\hline \multicolumn{11}{|c|}{$\begin{array}{l}\text { Patient or population: pregnant women } \\
\text { Setting: pregnant women } \\
\text { Intervention: cesarean } \\
\text { Comparison: vaginal delivery }\end{array}$} \\
\hline \multirow{2}{*}{$\begin{array}{l}\text { Outcomes: } \\
\text { Risk of } \\
\text { postpartum } \\
\text { depression } \\
\text { in people } \\
\text { with } \\
\text { cesarean }\end{array}$} & \multicolumn{2}{|c|}{$\begin{array}{l}\text { Anticipated absolute } \\
\text { effects1 }(95 \% \mathrm{Cl})\end{array}$} & \multirow{2}{*}{$\begin{array}{l}\text { Relative } \\
\text { effect } \\
(95 \% \mathrm{Cl})\end{array}$} & \multirow{2}{*}{$\begin{array}{l}\text { Number of } \\
\text { participants } \\
\text { (studies) }\end{array}$} & \multicolumn{6}{|c|}{ Quality assessment } \\
\hline & $\begin{array}{l}\text { Risk in } \\
\text { vaginal } \\
\text { delivery }\end{array}$ & $\begin{array}{l}\text { Risk with } \\
\text { Risk of } \\
\text { postpartum } \\
\text { depression } \\
\text { in people } \\
\text { with } \\
\text { cesarean }\end{array}$ & & & $\begin{array}{l}\text { Risk } \\
\text { of bias }\end{array}$ & Inconsistency & Indirectness & Imprecision & $\begin{array}{l}\text { Publication } \\
\text { bias }\end{array}$ & $\begin{array}{l}\text { Overall } \\
\text { quality of } \\
\text { evidence }\end{array}$ \\
\hline $\begin{array}{l}\text { 2days } \\
\text { postpartum }\end{array}$ & $\begin{array}{l}252.16 \\
\text { per } \\
1000\end{array}$ & $\begin{array}{l}335.94 \text { per } \\
1000\end{array}$ & $\begin{array}{l}\text { RR } 1.33 \\
(1.07 \text { to } \\
1.65)\end{array}$ & $\begin{array}{l}256(86 \\
\text { observational } \\
\text { study) }\end{array}$ & $\begin{array}{l}\text { Not } \\
\text { serious }\end{array}$ & Not serious & Not serious & Not serious & None & $\bigoplus \bigoplus_{\text {LOW }}$ \\
\hline $\begin{array}{l}\text { 2weeks } \\
\text { postpartum }\end{array}$ & $\begin{array}{l}109.24 \\
\text { per } \\
1000\end{array}$ & $\begin{array}{l}216.87 \text { per } \\
1000\end{array}$ & $\begin{array}{l}\text { RR } 1.99 \\
(1.15 \text { to } \\
3.42)\end{array}$ & $\begin{array}{l}415(90 \\
\text { observational } \\
\text { study) }\end{array}$ & $\begin{array}{l}\text { Not } \\
\text { serious }\end{array}$ & Not serious & Not serious & Not serious & None & $\bigoplus \bigoplus \bigoplus$ \\
\hline $\begin{array}{l}\text { 2months } \\
\text { postpartum }\end{array}$ & $\begin{array}{l}240.00 \\
\text { per } \\
1000\end{array}$ & $\begin{array}{l}206.67 \\
\text { per } 1000\end{array}$ & $\begin{array}{l}\text { RR } \\
0.86(0.56 \\
\text { to } 1.32)\end{array}$ & $\begin{array}{l}150(31 \\
\text { observational } \\
\text { study) }\end{array}$ & $\begin{array}{l}\text { Not } \\
\text { serious }\end{array}$ & Not serious & Not serious & Not serious & None & $\bigoplus_{\text {LOW }}^{\oplus}$ \\
\hline $\begin{array}{l}\text { 4months } \\
\text { postpartum }\end{array}$ & $\begin{array}{l}146.67 \\
\text { per } \\
1000\end{array}$ & $\begin{array}{l}166.67 \\
\text { per } 1000\end{array}$ & $\begin{array}{l}\text { RR } \\
1.14(0.67 \\
\text { to } 1.92)\end{array}$ & $\begin{array}{l}150(25 \\
\text { observational } \\
\text { study) }\end{array}$ & $\begin{array}{l}\text { Not } \\
\text { serious }\end{array}$ & Not serious & Not serious & Not serious & None & $\bigoplus_{\text {LOW }}^{\oplus}$ \\
\hline $\begin{array}{l}1 \text { year } \\
\text { postpartum }\end{array}$ & $\begin{array}{l}4.44 \\
\text { per } \\
1000\end{array}$ & $\begin{array}{l}5.86 \text { per } \\
1000\end{array}$ & $\begin{array}{l}\text { RR } 1.32 \\
(0.93 \text { to } \\
1.87)\end{array}$ & $\begin{array}{l}12619(74 \\
\text { observational } \\
\text { study) }\end{array}$ & $\begin{array}{l}\text { Not } \\
\text { serious }\end{array}$ & Not serious & Not serious & Not serious & None & $\bigoplus_{\text {LOW }}^{\oplus}$ \\
\hline
\end{tabular}

${ }^{1}$ The risk in the intervention group (and its $95 \%$ confidence interval) is based on the assumed risk in the comparison group and the relative effect of the interv its $95 \% \mathrm{Cl}$ ).

Cl: Confidence interval; RR: Risk ratio

GRADE Working Group grades of evidence

High quality: We are very confident that the true effect lies close to that of the estimate of the effect

Moderate quality: We are moderately confident in the effect estimate: The true effect is likely to be close to the estimate of the effect, but there is a possibility substantially different

Low quality: Our confidence in the effect estimate is limited: The true effect may be substantially different from the estimate of the effect

Very low quality: We have little confidence in the effect estimate: The true effect is likely to be substantially different from the estimate of effect

\section{Discussion}

\subsection{Clinical Implications}

To the author's best knowledge, few systematic reviews and meta-analyses examined the relationship between delivery mode and postpartum depression. We analyzed the evidence about the postpartum depression rates in CS and VD, respectively. Our study not only supported the hypothesis that delivery type is relevant to the incidence depression in the postpartum period, but also concluded that CS is associated with a higher risk of postpartum depression symptoms than VD.

Postpartum depression is a multi-factorial behavior related to delivery mode [10], maternal age [11], season of delivery [12], and social support [13]. The mode of delivery has substantial impact on physical and psychological health [14] and is one of the most concerned variates in research about postpartum depression [15]. However, few studies focused on the association between the type of delivery and the incidence of postpartum depression. To examine the causal relationship between delivery mode and postpartum depression, our study included only cohort studies. Generally, ordinary meta-analyses on the efficacy of interventions obtain high quality evidence from randomized controlled trials [5]. However, randomized trials are not suitable for our study, beause 
the duration of randomized trials is often too short to explore long time or rare adverse consequences [16]. It is also impossible to randomize mothers into the categories 'CS' or 'VD'. Therefore, only cohort studies are included in our study and the obtained results are shown to be effective. All included cohort studies may reveal the effects of delivery mode on maternal mental disorders and further effects of the different modes of delivery on postpartum depression.

\subsection{Methodological Considerations}

From the methodological perspective, there are some limitations in our study. Firstly, only four cohort studies were identified, which may make the results of the funnel plot unreliable since the results might be influenced by the low statistical power of insufficient studies [17]. In addition, the included studies were limited to the northern hemisphere. Whether the risk of postpartum depression differs in patients with different delivery modes elsewhere in the world is unclear [18]. Secondly, we were unable to conduct subgroup analyses in terms of maternal age, season of delivery, social support, indications for cesarean section, and neonatal admission to the intensive care unit because the selected cohort studies did not offer enough information. Thirdly, although the kappa statistics for the agreement of interobserver reliability seemed acceptable, nondifferential misclassification or bias data extraction still may have occurred. Fourthly, according to our obtained results from GRADE assessment, the evidence from the included observational studies was initially rated as low quality and later not upgrade $[5,19]$. More research with precision and abundant data in the future are likely to increase the quality of the evidence. Fifthly, only one study indicated that postpartum depression is more common in vaginal delivery than cesarean section [6]. Although the VD group showed a more decreased Edinburgh Postnatal Depression Scale (EPDS) from 2 months to 4 months after delivery, it is difficult to have enough information to estimate the 2 months postpartum depression in this study. Sixthly, this study's search keyword is "vaginal delivery OR normal delivery OR normal vaginal delivery OR natural delivery OR vacuum extraction". However, there are several types vaginal delivery, including spontaneous vaginal delivery (SVD), assisted vaginal delivery (AVD) or instrumental vaginal delivery, induced vaginal delivery, and normal vaginal delivery (NVD), which means that we might missed some of the studies related to this topic. Seventhly, from the included VD types might cause issues such as vaginal tears, retained placenta, postpartum hemorrhage (PPH), and shoulder dystocia could lead to maternal physical and psychical problems. Mothers' states are also very dependent on the baby's condition; we do not focus on the maternal population whose babies had abnormalities. Finally, Chen et al (2017) included most of the numbers, however, their study did not show the significance result. We also have a funnel plot (Fig. 3) to prove there is no publication bias.

\subsection{Conclusions}

Although the available best evidence supports an association between delivery mode and postpartum depression, more large-scale cohort studies are required to further reveal the relationship between the mode of delivery and depression in the postpartum period. Future studies also may divide the delivery modes into detailed modes such as elective cesarean delivery, emergency cesarean delivery [20], planned vaginal delivery, assisted vaginal delivery, spontaneous vaginal delivery [21,22], uncomplicated spontaneous vaginal delivery, complicated vaginal delivery [23], to study the role of delivery modes in postpartum.

\section{Abbreviations}

CS

cesarean section

VD

vaginal delivery

SVD

spontaneous vaginal delivery

\section{AVD}

assisted vaginal delivery

NVD

normal vaginal delivery

PPH

postpartum hemorrhage

RR

Risk Ratio

$\mathrm{Cl}$

confidence interval 
Newcastle-Ottawa Scale

GRADE

Grading of Recommendations Assessment, Development, and Evaluation

EPDS

Edinburgh Postnatal Depression Scale

\section{Declarations}

\section{Ethics approval and consent to participate}

Not applicable.

Consent to publish

Not applicable.

\section{Availability of data and materials}

All data underlying the findings are within the paper.

The authors declare that they have no competing interests.

This review had no funding.

Authors' Contributions

YXC, THT and CWC designed and planned the research questions and methods. YXC, PZ, ZLJ, XFY and PEC conducted data extraction and analysis. YXC prepared the manuscript. All authors (YXC, PZ, ZLJ, XFY, PEC, THT, CWC) provided feedback on the manuscript. All authors read and approved the final manuscript.

The authors thank for the feedback Professor Lei Xue and Professor Longtian Chen. The authors also thank the Sunflower Statistical Consulting Company, Kaohsiung, Taiwan for statistical advice.

\section{References}

1. Houston KA, Kaimal AJ, Nakagawa S, Gregorich SE, Yee LM, Kuppermann M. Mode of delivery and postpartum depression: the role of patient preferences. Am J Obstet Gynecol. 2015;212:229.e1-229.e7.

2.Rauh C, Beetz A, Burger P, et al. Delivery mode and the course of pre- and postpartum depression. Arch Gynecol Obstet. 2012;286:1407-1412.

3.Chang S, Chen K, Ho H, et al. Depressive symptoms, pain, and sexual dysfunction over the first year following vaginal or cesarean delivery: A prospective longitudinal study. Int J Nurs Stud. 2015;52:1433-1444.

4.Luchini C, Stubbs B, Solmi M, Veronese N. Assessing the quality of studies in meta-analyses: Advantages and limitations of the Newcastle Ottawa Scale. World J Metaanal.2017;5:80.

5.Chi C, Chen T, Wang S, Tung T. Risk of Suicidality in People with Psoriasis: A Systematic Review and Meta-Analysis of Cohort Studies. Am J Clin Dermatol. 2017;18:621-627.

6.Sadat Z, Kafaei AM, Masoudi AN, Abbaszadeh F, Karimian Z, Taherian A. Effect of mode of delivery on postpartum depression in Iranian women. J Obstet Gynaecol Res. 2014;40:172-177.

7.Xie R, Lei J, Wang S, Xie H, Walker M, Wen SW. Cesarean Section and Postpartum Depression in a Cohort of Chinese Women with a High Cesarean Delivery Rate. J Women Health. 2011;20:1881-1886.

8.Chen HH, Lai JC, Hwang SJ, Huang N, Chou YJ, Chien LY. Understanding the relationship between cesarean birth and stress, anxiety, and depression after childbirth: A nationwide cohort study. Birth. 2017;44:369-376.

9.Benzouina S, Boubkraoui ME, Mrabet M, et al. Fetal outcome in emergency versus elective cesarean sections at Souissi Maternity Hospital, Rabat, Morocco. Pan Afr Med J. 2016;23:197.

10.Unsal Atan Ş, Ozturk R, Gulec Satir D, et al. Relation between mothers' types of labor, birth interventions, birth experiences and postpartum depression: A multicentre follow-up study. Sex Reprod Healthc. 2018;18:13-18. 
11.Petrosyan D, Armenian HK, Arzoumanian K. Interaction of maternal age and mode of delivery in the development of postpartum depression in Yerevan, Armenia. J Affect Disorders. 2011;135:77-81.

12.Yang S, Shen L, Ping T, Wang Y, Chien C. The delivery mode and seasonal variation are associated with the development of postpartum depression. $\mathrm{J}$ Affect Disorders. 2011;132:158-164.

13.Chaaya M, Campbell OMR, El Kak F, Shaar D, Harb H, Kaddour A. Postpartum depression: prevalence and determinants in Lebanon. Arch Womens Ment Health. 2002;5:65-72.

14.Ukpong DI, Owolabi AT. Postpartum emotional distress: a controlled study of Nigerian women after caesarean childbirth. J Obstet Gynaecol. 2006;26:127129

15. Hou L, Hellerstein S, Vitonis A, et al. Cross sectional study of mode of delivery and maternal and perinatal outcomes in mainland China. Plos One. 2017;12:e0171779.

16.Congdon JL, Adler NE, Epel ES, Laraia BA, Bush NR. A Prospective Investigation of Prenatal Mood and Childbirth Perceptions in an Ethnically Diverse, LowIncome Sample. Birth. 2016;43:159-166.

17.Chen TH, Tung TH, Chen PS, et al. The Clinical Effects of Aromatherapy Massage on Reducing Pain for the Cancer Patients: Meta-Analysis of Randomized Controlled Trials. Evid Based Complement Alternat Med. 2016;2016:9147974.

18.Leiberman JR, Fraser D, Mazor M, et al. Breech presentation and cesarean section in term nulliparous women. Eur J Obstet Gynecol Reprod Biol. 1995;61:111-1115.

19.Eisenach JC, Pan PH, Smiley R, Lavand Homme P, Landau R, Houle TT. Severity of acute pain after childbirth, but not type of delivery, predicts persistent pain and postpartum depression. Pain. 2008;140:87-94.

20.Zanardo V, Giliberti L, Giliberti E, Volpe F, Straface G, Greco P. The role of elective and emergency cesarean delivery in maternal postpartum anhedonia, anxiety, and depression. Int J Gynecol Obstet. 2018;143:374-378.

21.Patel RR, Murphy DJ, Peters TJ. Operative delivery and postnatal depression: a cohort study. BMJ. 2005;330:879.

22.Weisman O, Granat A, Gilboa-Schechtman E, et al. The experience of labor, maternal perception of the infant, and the mother's postpartum mood in a lowrisk community cohort. Arch Womens Ment Health.2010;13:505-513.

23.Faisal-Cury A, Menezes PR. Type of delivery is not associated with maternal depression. Arch Womens Ment Health.2019;22:631-635.

\section{Figures}




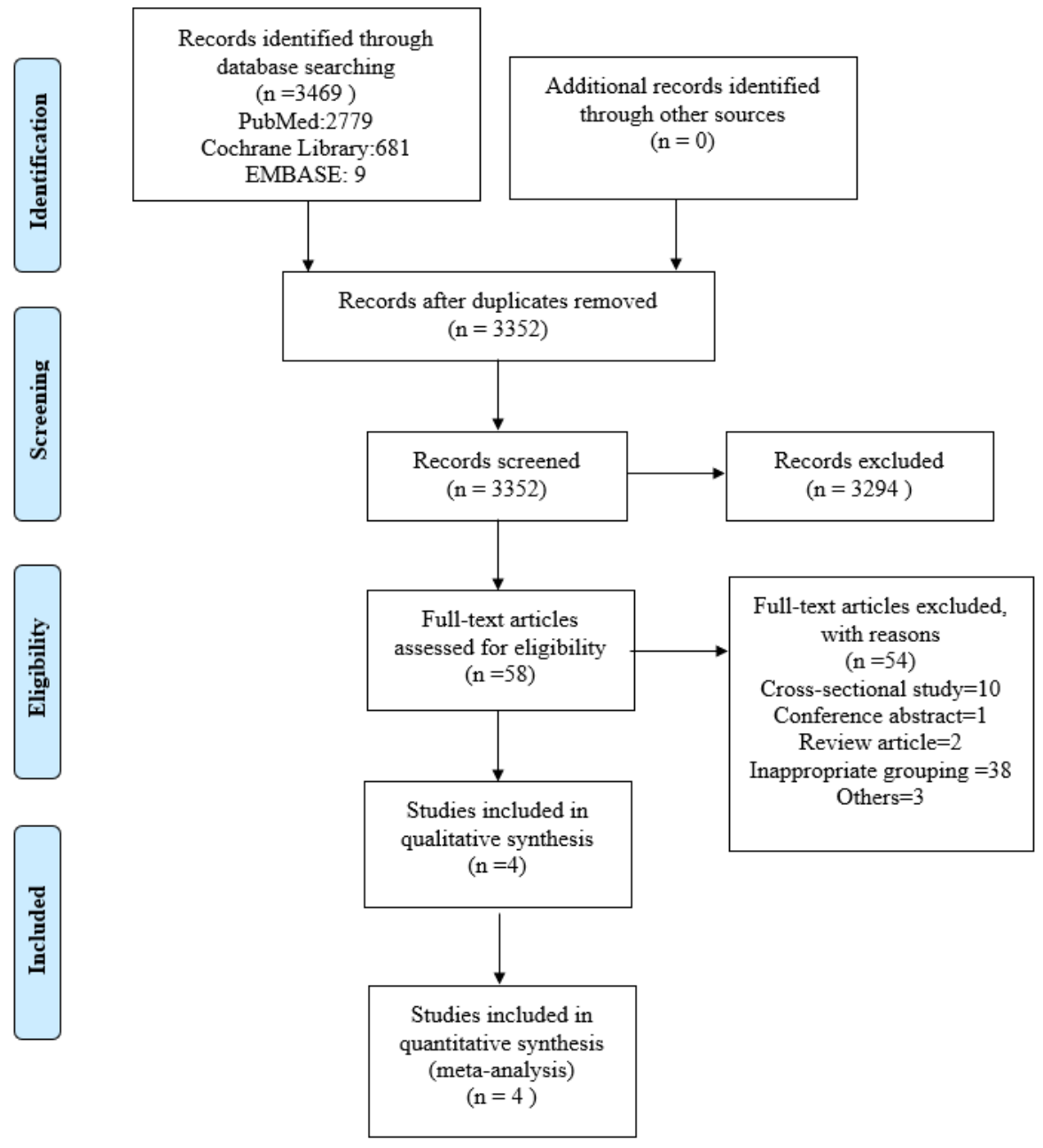

Figure 1

PRISMA study flow chart

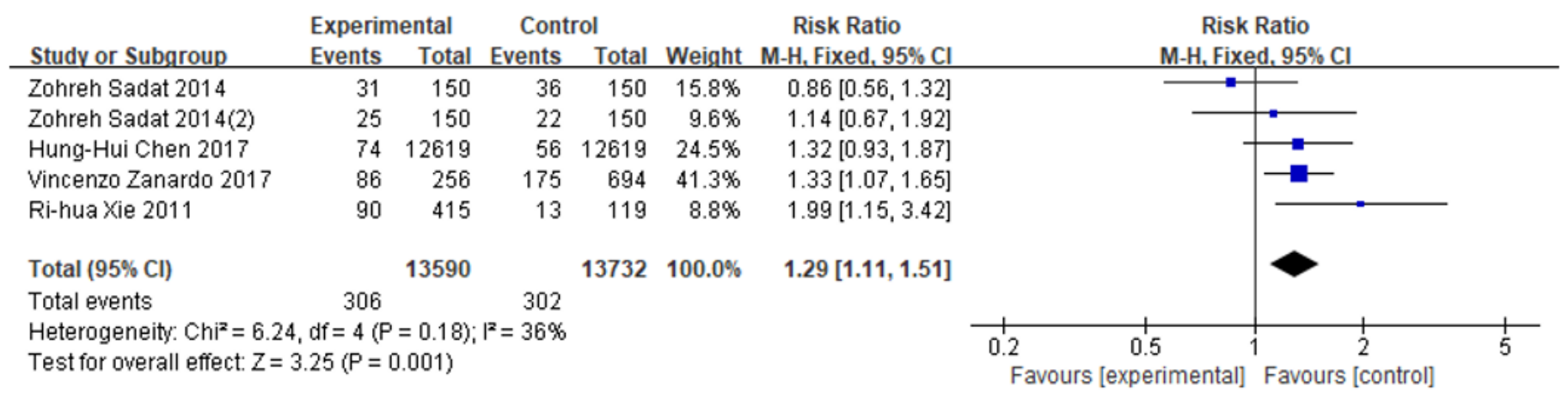

Figure 2

Risk ratio of postpartum depression in patients with cesarean section. (Experimental: cesarean section, Control: vaginal delivery Cl: confidence interval, SE: standard error) 


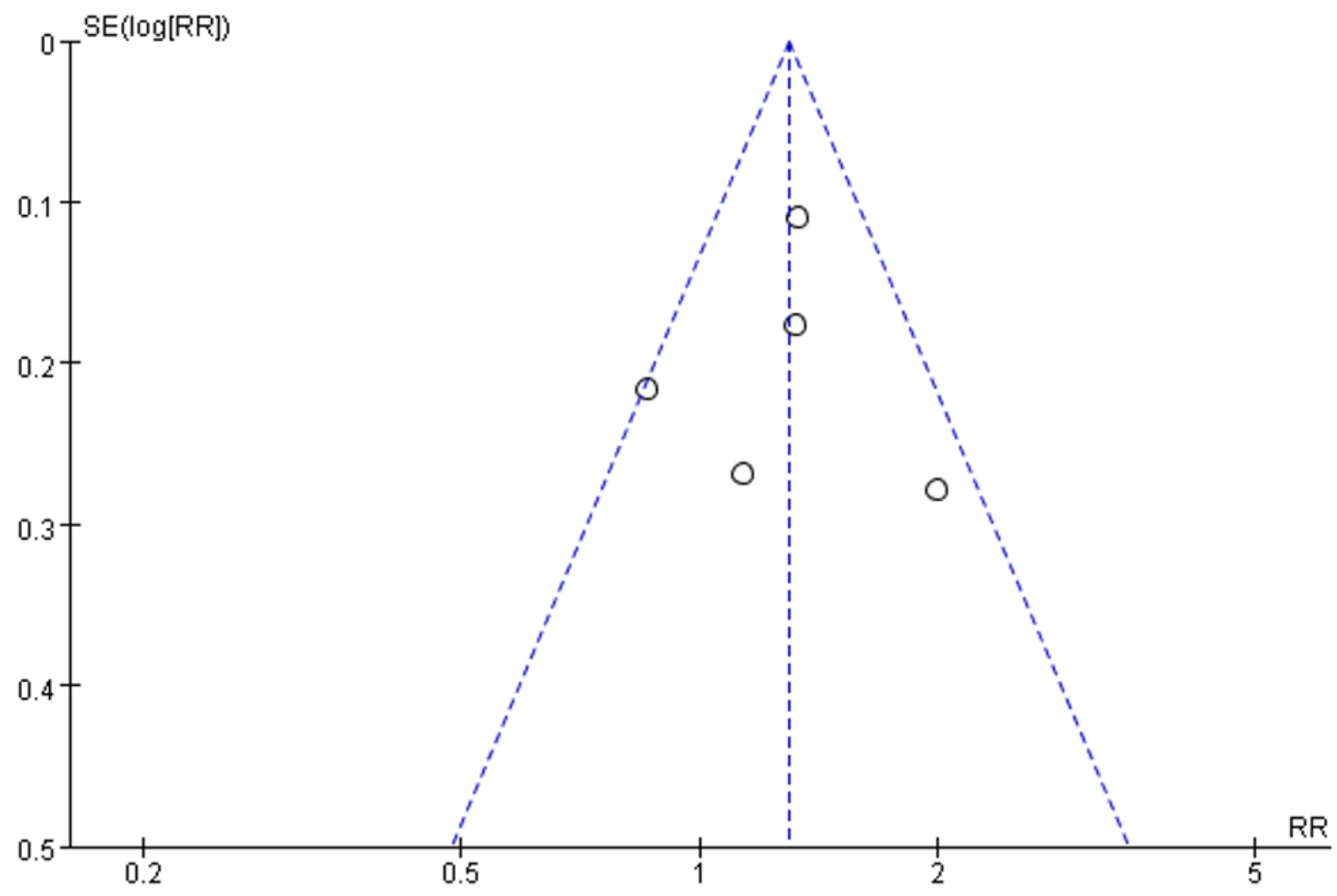

Figure 3

Funnel plot

\section{Supplementary Files}

This is a list of supplementary files associated with this preprint. Click to download.

- PRISMA2009checklist.doc 